\title{
Compensation of Hemispheric Albedo Asymmetries by Shifts of the ITCZ and Tropical Clouds
}

\author{
Aiko VOIGT* AND BJORN STEVENS \\ Max Planck Institute for Meteorology, Hamburg, Germany \\ JÜRGEN BADER \\ Max Planck Institute for Meteorology, Hamburg, Germany, and Bjerknes Centre for Climate Research, \\ Uni Research, Bergen, Norway \\ THORSTEN MAURITSEN \\ Max Planck Institute for Meteorology, Hamburg, Germany
}

(Manuscript received 1 April 2013, in final form 17 September 2013)

\begin{abstract}
Despite a substantial hemispheric asymmetry in clear-sky albedo, observations of Earth's radiation budget reveal that the two hemispheres have the same all-sky albedo. Here, aquaplanet simulations with the atmosphere general circulation model ECHAM6 coupled to a slab ocean are performed to study to what extent and by which mechanisms clouds compensate hemispheric asymmetries in clear-sky albedo. Clouds adapt to compensate the imposed asymmetries because the intertropical convergence zone (ITCZ) shifts into the dark surface hemisphere. The strength of this tropical compensation mechanism is linked to the magnitude of the ITCZ shift. In some cases the ITCZ shift is so strong as to overcompensate the hemispheric asymmetry in clear-sky albedo, yielding a range of climates for which the hemisphere with lower clear-sky albedo has a higher all-sky albedo. The ITCZ shift is sensitive to the convection scheme and the depth of the slab ocean. Cloud-radiative feedbacks explain part of the sensitivity to the convection scheme as they amplify the ITCZ shift in the Tiedtke (TTT) scheme but have a neutral effect in the Nordeng (TNT) scheme. A shallower slab ocean depth, and thereby reduced thermal inertia of the underlying surface and increased seasonal cycle, stabilizes the ITCZ against annual-mean shifts. The results lend support to the idea that the climate system adjusts so as to minimize hemispheric albedo asymmetries, although there is no indication that the hemispheres must have exactly the same albedo.
\end{abstract}

\section{Introduction}

Earth's planetary albedo, hereafter albedo, describes the fraction of top-of-atmosphere (TOA) reflected to incident shortwave irradiance. It is one of the most fundamental and fascinating properties of the climate system. By controlling the energy input from the sun, it constrains the longwave energy loss to space and the surface climate. Its susceptibility to change governs

\footnotetext{
* Current affiliation: Laboratoire de Météorologie Dynamique, IPSL, UPMC, Paris, France.

Corresponding author address: Aiko Voigt, Max Planck Institute for Meteorology, Bundesstr. 53, 20146 Hamburg, Germany. E-mail: aiko.voigt@lmd.jussieu.fr
}

many aspects of projected future warm climates (e.g., Bony et al. 2006; Andrews et al. 2012) as well as past cold climates (e.g., Pierrehumbert et al. 2011; Voigt and Abbot 2012). Small changes in albedo translate to large changes in the TOA energy budget. For example, an increase of Earth's current albedo from $29 \%$ to $30 \%$ would almost compensate the radiative forcing of a $\mathrm{CO}_{2}$ doubling. Climate models project albedo changes of several percent in response to the anthropogenic release of $\mathrm{CO}_{2}$ (Bender 2011).

Our understanding of albedo, however, remains limited as there is no general theory of what determines albedo and its susceptibility to change. Albedo is not an external parameter but rather an emergent property of the climate system that arises through a multitude of still poorly understood processes and interactions. It depends 
on the atmospheric and surface characteristics, such as the distribution and properties of clouds, water vapor, ice, and snow, all of which respond to and affect climate change. Because clouds are the largest contributor to Earth's albedo (Ramanathan 1987; Ramanathan et al. 1989; Donohoe and Battisti 2011) and because they are organized by planetary-scale circulation systems, the quest for an albedo theory may benefit from studying how planetary-scale circulation systems and clouds are linked. Motivated by observations (see below), this manuscript explores this link on the hemispheric scale, which is the largest regional scale.

Satellite-based measurements of Earth's TOA irradiances by the Clouds and the Earth's Radiant Energy System (CERES; Wielicki et al. 1996; Loeb et al. 2009) revealed two intriguing characteristics of Earth's albedo. First, interannual variations of global-mean albedo were found to not exceed $0.4 \%$ of the long-term value, which is remarkably small in the light of internal climate variations such as the El Niño-Southern Oscillation (Kato 2009). Second, the Northern and Southern Hemispheres have the same albedo despite a large hemispheric asymmetry in land, which introduces a large hemispheric asymmetry in clear-sky albedo. (Voigt et al. 2013). The hemispheric symmetry in albedo measured by CERES is in line with previous less accurate and less precise measurements (Vonder Haar and Suomi 1971; Ramanathan 1987; Zhang and Rossow 1997; Hatzianastassiou et al. 2004a,b), which suggests that the symmetry is not a measurement artifact but a robust feature of modern Earth. Voigt et al. (2013) demonstrated that the symmetry is nontrivial in the sense that it cannot be explained by the statistical properties of the observed TOA-reflected shortwave irradiance. This raises the possibility that the hemispheric albedo symmetry is maintained by dynamical mechanisms. If this is the case, understanding how these mechanisms operate would seem critical to a fundamental understanding of the climate system and thus motivates the questions developed below.

Climate models do not reproduce the observed hemispheric symmetry (Voigt et al. 2013). They therefore cannot be used to conclusively determine whether the symmetry is indeed a constraint or rather accidental. However, they allow us to investigate if there are mechanisms that compensate hemispheric asymmetries in clear-sky albedo. In this study, we search and quantify possible compensation mechanisms through aquaplanet simulations with a comprehensive atmosphere general circulation model coupled to a slab ocean. We introduce various hemispheric asymmetries in clear-sky albedo by increasing the surface albedo in one hemisphere and decreasing it by the same amount in the other hemisphere.
To the extent that compensation mechanisms indeed exist, they must-by definition-be associated with changes in the distribution or optical properties of clouds. The main goal of our simulations thus is to monitor how hemispheric asymmetries in clear-sky albedo translate to hemispheric asymmetries in all-sky albedo and to explore how these are linked to clouds and the atmospheric circulation. ${ }^{1}$ We find that shifts of the intertropical convergence zone (ITCZ) and high tropical clouds act such as to compensate the imposed hemispheric albedo asymmetries, albeit not exactly, which further motivates us to study in detail how clouds and the seasonal cycle modulate these ITCZ shifts. The link of the ITCZ shifts to hemispheric asymmetries in longwave and net TOA irradiances (Kang et al. 2008, 2009; Frierson and Hwang 2012; Cvijanovic et al. 2013; Cvijanovic and Chiang 2013; Donohoe et al. 2013b) is discussed herein only insofar as to understand the magnitude of the ITCZ shift.

The remainder of this paper is organized as follows. The simulation framework is described in section 2 . Section 3 discusses conceptually how clouds affect the hemispheric albedo asymmetry and introduces a benchmark for compensation mechanisms. Section 4 shows that clouds change so as to compensate the imposed hemispheric asymmetry in clear-sky albedo in our simulations. Section 5 argues that the compensation necessarily results from the response of the tropical circulation, most notably the ITCZ, to the imposed hemispheric asymmetry in clear-sky albedo. Section 6 examines to what extent the ITCZ shift and compensation strength depends on cloud-radiative feedbacks, and section 7 addresses the influence of the convection scheme and the slab ocean depth. Conclusions are presented in section 8 .

\section{Simulation framework}

We use the comprehensive atmosphere general circulation model ECHAM6 (Stevens et al. 2013) in aquaplanet configuration coupled to a slab ocean. In the aquaplanet configuration, continents are removed. Coupling the model to a slab ocean ensures that the surface energy balance is closed, which allows surface temperatures to feel the imposed asymmetries in clear-sky albedo and to interact with changes in clouds and the atmospheric circulation. To generate hemispheric asymmetries in clear-sky albedo, we increase the surface albedo in

\footnotetext{
${ }^{1}$ Clear-sky albedo is the albedo that Earth would have if clouds were transparent to radiation. The actual albedo of Earth takes into account the radiative effect of clouds and is often referred to as all-sky albedo. We adopt this terminology throughout the paper.
} 


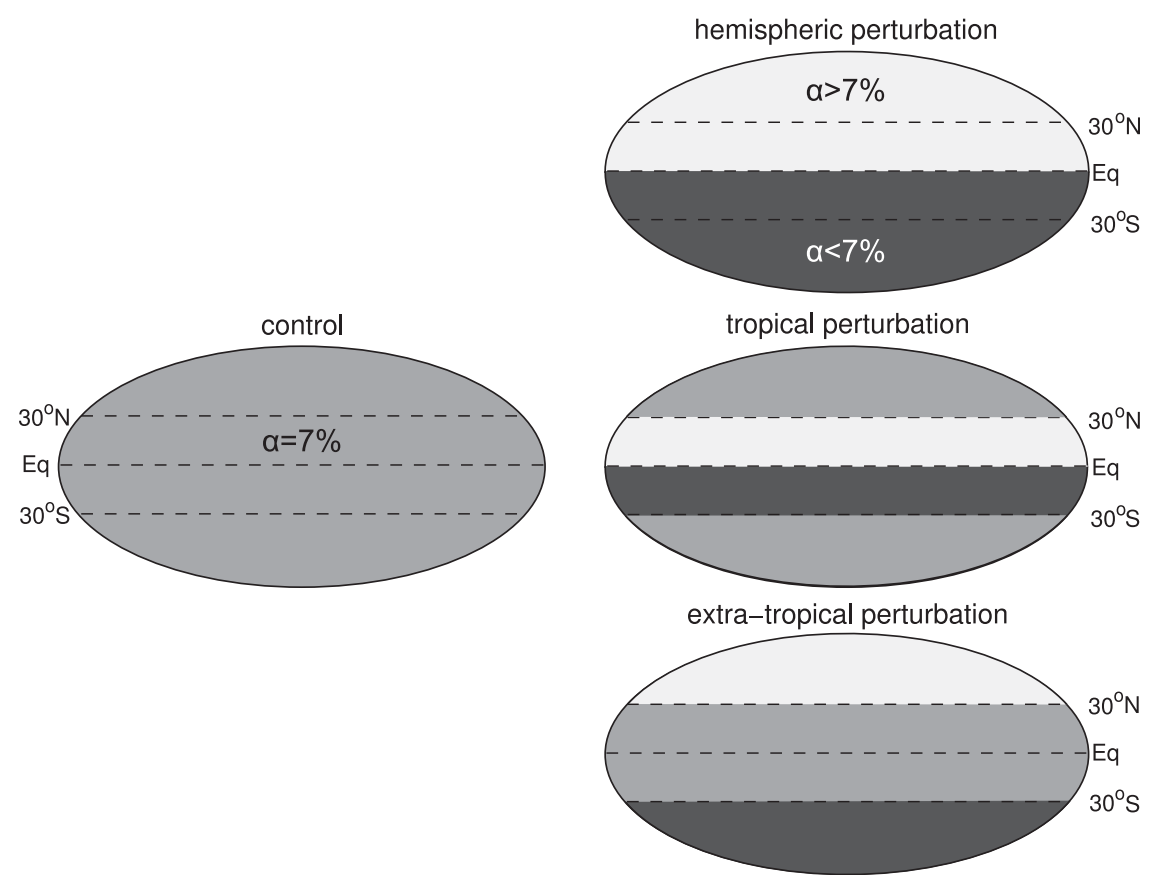

FIG. 1. Prescribed surface albedo. (left) Control climate with globally uniform surface albedo of $7 \%$. (right) Perturbed climates with increased surface albedo in the $\mathrm{NH}$ and decreased surface albedo in the SH. These climates include (top) hemispheric surface albedo perturbations as well as (middle) perturbations that are restricted to the tropics $\left(30^{\circ} \mathrm{N}-30^{\circ} \mathrm{S}\right)$ and (bottom) extratropics (poleward of $30^{\circ} \mathrm{N} / \mathrm{S}$ ), respectively.

the Northern Hemisphere and decrease it by the same amount in the Southern Hemisphere (Fig. 1). Because the climate system feels hemispheric asymmetries in albedo through hemispheric asymmetries in the TOA-reflected shortwave irradiance, we will discuss albedo asymmetries in terms of the TOA-reflected shortwave irradiance. For the sake of brevity, we will use the term "reflection" instead of TOA-reflected shortwave irradiance.

The surface albedo perturbations range from $1 \%$ to $7 \%$, with $7 \%$ being the maximum perturbation, which ensures that the surface albedo remains nonnegative. The efficiency by which surface albedo perturbations trigger circulation and cloud changes might depend on their location because cloud-masking effects and the solar insolation vary with latitude (see section 3 ). We therefore use hemispheric perturbations as well as perturbations restricted to the tropics $\left(30^{\circ} \mathrm{N}-30^{\circ} \mathrm{S}\right)$ or extratropics (poleward of $30^{\circ}$; see Fig. 1). Being asymmetric with respect to the equator, the perturbations exhibit almost no global-mean top-of-atmosphere radiative forcing and nearly preserve the global-mean climate. For all perturbations, global-mean surface temperature stays within $2 \mathrm{~K}$, global-mean cloud cover stays within $1 \%$, and global-mean all-sky and clear-sky TOA irradiances stay within $3 \mathrm{~W} \mathrm{~m}^{-2}$ of the respective control simulation; most perturbations actually yield smaller global-mean changes. ${ }^{2}$ In particular, globalmean changes are always at least a factor of 10 smaller than the hemispheric asymmetries studied here.

In the standard version of ECHAM6, the ocean surface albedo depends on the solar zenith angle (diffuse versus direct radiation) and wavelength (visible versus near infrared) of the downward surface shortwave irradiance. Here, we remove these dependencies and fix the surface albedo of the control simulations to $7 \%$ everywhere. To focus on the role of clouds, sea ice formation is inhibited and the ocean is allowed to cool below freezing. The prescribed ocean energy transport is zonally symmetric and constant in time (Fig. 2). Its meridional profile follows Eq. (1) of Rose and Ferreira (2013) and is given by (in units of petawatts; $\varphi$ is latitude)

$$
H=8 \sin \varphi \cos ^{6} \varphi .
$$

Because the transport is symmetric about the equator, it does not contribute to hemispheric asymmetries. The

\footnotetext{
${ }^{2}$ Global-mean control values are about $20^{\circ} \mathrm{C}$ for surface temperature, $68 \%$ for cloud cover, and $95 \mathrm{~W} \mathrm{~m}^{-2}$ for TOA all-sky reflected shortwave irradiance. The latter is equivalent to an all-sky albedo of $28 \%$.
} 


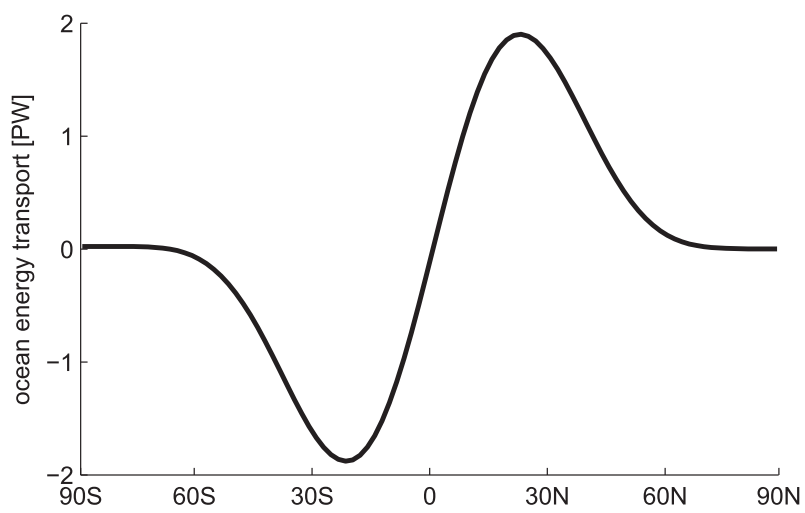

FIG. 2. Prescribed meridional ocean energy transport. Northward transport is positive. The ocean energy transport is constant in time and the same for all simulations.

transport peaks at $1.9 \mathrm{PW}$ at $22^{\circ} \mathrm{N} / \mathrm{S}$ and captures the broad characteristics of the observed transport (Trenberth and Caron 2001), albeit the latitude at which it maximizes is slightly more poleward and the highlatitude transport is smaller than in observations. Most simulations use a 50-m-deep slab ocean, but simulations with a shallower ocean of 30-m depth are also analyzed. The use of a slab ocean enables us to study how the planetary-scale atmospheric circulation and clouds respond to a large range in hemispheric asymmetries in clear-sky albedo, and the degree to which the response depends on the location of the surface albedo perturbation, the slab ocean depth, and the representation of atmospheric convection (see below). This is not to say that the ocean is unimportant as the ocean circulation impacts the ITCZ structure (e.g., Codron 2012; Fuĉkar et al. 2013; Marshall et al. 2013) and the atmospheric cross-equatorial energy transport (e.g., Jayne and Marotzke 2001; Held 2001), both of which will turn out to affect the degree of albedo compensation. However, as a first step this manuscript explores the behavior of the atmosphere in the absence of perturbations to the lateral energy transport in the ocean.

Modeling convection remains a challenge for global climate models, and convection schemes have been shown to affect many aspects of the tropical climate (e.g., Kang et al. 2008; Möbis and Stevens 2012; Crueger et al. 2013). We therefore perform simulations with the convection schemes of Nordeng (1994) as well as Tiedtke (1989). The Nordeng (TNT) scheme is ECHAM6's standard convection scheme and is based on the Tiedtke (TTT) scheme that is also implemented in the model. The TNT scheme uses the representation of shallow and midlevel convection of the TTT scheme but modifies TTT's treatment of deep convection [hence the name Tiedtke-Nordeng-Tiedtke (TNT)] through changes in the representation of entrainment, detrainment, and cloud-base mass flux (Möbis and Stevens 2012). Despite the fact that the two schemes are related, the differences between them are large enough to cause fundamentally different ITCZ structures in ECHAM6 simulations driven by prescribed sea surface temperatures, with the TNT scheme favoring a single and the TTT scheme favoring a double ITCZ (Möbis and Stevens 2012).

The solar constant is prescribed as $1361 \mathrm{~W} \mathrm{~m}^{-2}$, and the orbit is specified to be circular with $23.5^{\circ}$ obliquity. A 360 -day calendar is used. Greenhouse gases are set to preindustrial concentration values $\left(\mathrm{CO}_{2}=278 \mathrm{ppmv}\right.$, $\mathrm{CH}_{4}=650$ ppbv, $\mathrm{N}_{2} \mathrm{O}=270 \mathrm{ppbv}$, and no CFCs). Aerosol radiative effects are not accounted for. For ozone, annual-mean present-day values symmetrized about the equator are used. The horizontal resolution of ECHAM6 is set to $\mathrm{T} 63$ (equivalent to $1.875^{\circ}$ at the equator). The vertical extent of the atmosphere is distributed over 47 levels, with the model top at $0.01 \mathrm{hPa}$ and 24 levels below $150 \mathrm{hPa}$. This configuration of ECHAM6 corresponds to the low resolution (LR) version described by Stevens et al. (2013). The time step is $450 \mathrm{~s}$. All simulations are integrated for 20 years to reach stationarity and then integrated for at least 10 more years to accumulate statistics.

ECHAM6 is known to have energy leaks related to (among other things) small inconsistencies in the treatment of thermodynamic processes (Stevens et al. 2013). Similar problems are evident in other models (e.g., Lucarini and Ragone 2011; Voigt et al. 2011). However, the simulations presented here conserve energy within $0.5 \mathrm{~W} \mathrm{~m}^{-2}$, implying that the simulated hemispheric asymmetries are not noticeably affected by energy leaks.

\section{Cloud masking, cloud response, and a benchmark for compensation mechanisms}

Before analyzing the simulations, it is helpful to think about how clouds translate a hemispheric asymmetry in the clear-sky reflection into a hemispheric asymmetry in the all-sky reflection. At each latitude, the all-sky reflection can be written as the sum of clear-sky and cloud components,

$$
R(\varphi)=f(\varphi) R_{\text {cloud }}(\varphi)+[1-f(\varphi)] R_{\text {clear }}(\varphi),
$$

with the all-sky reflection $R$, cloud cover $f$, and latitude $\varphi$. The term $R_{\text {cloud }}$ denotes reflection from clouds, and $R_{\text {clear }}$ denotes reflection from clear skies. Given Eq. (2), the hemispheric asymmetry in the all-sky reflection can be expressed as 


$$
\begin{aligned}
\Delta R & =\int_{0}^{\pi / 2}[R(\varphi)-R(-\varphi)] d \sin \varphi \\
& =\Delta R_{\text {clear }}+2 \int_{0}^{\pi / 2}\left\{\left[\bar{R}_{\text {cloud }}(\varphi)-\bar{R}_{\text {clear }}(\varphi)\right] \delta f(\varphi)+\bar{f}(\varphi)\left[\delta R_{\text {cloud }}(\varphi)-\delta R_{\text {clear }}(\varphi)\right]\right\} d \sin \varphi .
\end{aligned}
$$

Here, $\Delta$ denotes the hemispheric asymmetry, defined as the Northern Hemisphere average minus the Southern Hemisphere average, and the overbar and $\delta$ denote the symmetric and antisymmetric components, for example, for cloud cover:

$$
\begin{aligned}
\bar{f}(\varphi) & =1 / 2[f(\varphi)+f(-\varphi)] \quad \text { and } \\
\delta f(\varphi) & =1 / 2[f(\varphi)-f(-\varphi)] .
\end{aligned}
$$

In terms of the above expressions, $f(\varphi)$ can be written as

$$
f(\varphi)=\bar{f}(\varphi)+\operatorname{sgn}(\varphi) \delta f(\varphi),
$$

where sgn denotes the sign function. Analogous expressions hold for $R_{\text {cloud }}$ and $R_{\text {clear }}$.

The decomposition in Eq. (3) illustrates how asymmetries in clouds can either damp or amplify hemispheric asymmetries in albedo. For example, if cloud coverage reduced in the hemisphere with large clear-sky reflection or increased in the hemisphere with small clear-sky reflection, then clouds would compensate, or dampen, the imposed hemispheric asymmetry. The degree of the compensation by cloud cover changes does not only depend on the magnitude of the cloud cover change itself, but also on the contrast between $R_{\text {cloud }}$ and $R_{\text {clear }}$ (measured in watts per meter squared). This suggests that tropical clouds are more efficient in compensating or creating hemispheric asymmetries in the clearsky reflection than extratropical clouds because solar insolation is higher in the tropics, which leads to a larger contrast. Moreover, shifts of tropical clouds across the equator would be especially efficient because the hemispherically asymmetric changes lead to a particularly large $\delta f$.

The decomposition in Eq. (3) illustrates that clouds mask hemispheric asymmetries in the clear-sky reflection. In the idealized case that clouds were independent of the hemispheric asymmetry in the clear-sky reflection and were completely symmetric with respect to the equator $\left(\delta f=0\right.$ and $\left.\delta R_{\text {cloud }}=0\right)$, the hemispheric asymmetry in the all-sky reflection would still be smaller than the hemispheric asymmetry in the clear-sky reflection. Cloud-masking effects thus imply that it can be misleading to simply compare the hemispheric asymmetries in the all-sky and clear-sky reflections when one looks for compensation mechanisms. Instead, one needs to define a benchmark. The benchmark is that hemispheric asymmetry in the all-sky reflection that one would obtain if clouds did not respond at all to the imposed hemispheric asymmetry in the clear-sky reflection. With this, a compensation mechanism is a mechanism that reduces the hemispheric asymmetry in the all-sky reflection below the benchmark. We define such a benchmark based on Eq. (3) using the cloud cover of the control simulation denoted with a superscript $c$ :

$$
\Delta R_{\text {ref }}=\Delta R_{\text {clear }}-2 \int_{0}^{\pi / 2} \bar{f}^{c}(\varphi) \delta R_{\text {clear }}(\varphi) d \sin \varphi .
$$

Because the control simulation is symmetric with respect to the equator, $f^{c}=\bar{f}^{c}$ and $R_{\text {cloud }}^{c}=\bar{R}_{\text {cloud }}^{c}$, and all terms that are proportional to cloud asymmetries vanish. Benchmarks based on shortwave radiation models such as the ones developed by Donohoe and Battisti (2011) or Taylor et al. (2007) were also explored. However, because they gave similar benchmark values, we use the simpler and more intuitive Eq. (4).

\section{Tropical clouds compensate hemispheric asymmetries in clear-sky reflection}

We start with simulations based on the TNT representation of convection and a 50-m-deep slab ocean. Figure 3 shows the hemispheric asymmetry in the all-sky reflection as a function of the hemispheric asymmetry in the clear-sky reflection for hemispheric (black), tropical (red), and extratropical (blue) perturbations. The dashed lines depict the benchmark values based on Eq. (4). The benchmarks are linear in the hemispheric asymmetry in the clear-sky reflection but depend on the location of the perturbation because cloud cover varies meridionally. For instance, the slope of the benchmark line is smallest for the case of extratropical perturbations as the extratropics are cloudier than the tropics. For a cloud-free planet the benchmark lines would approach the line with unit slope.

Clouds compensate hemispheric asymmetries in the clear-sky reflection. For all perturbations, the hemispheric asymmetry in the all-sky reflection is smaller than the benchmark. The compensation by clouds results largely from the tropics (Fig. 3b), while the extratropic clouds contribute to the compensation for tropical but not for extratropical perturbations. Surprisingly, clouds do not only compensate but overcompensate the 

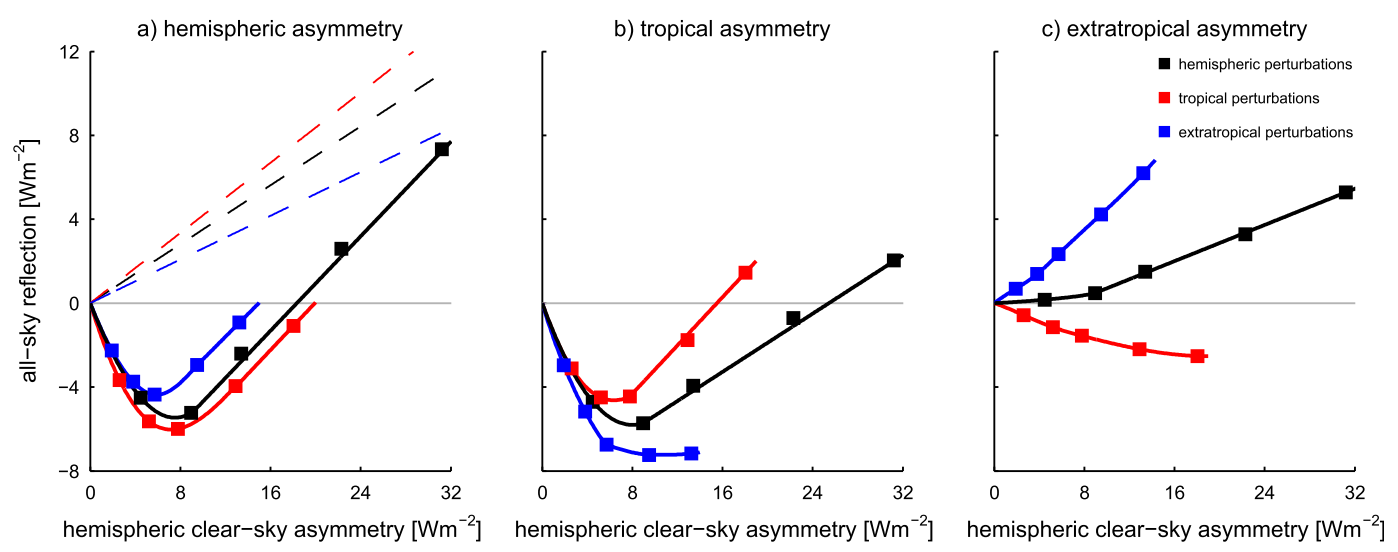

FIG. 3. (a) Hemispheric asymmetry in the all-sky reflection in dependence of the hemispheric asymmetry in the clear-sky reflection for hemispheric, tropical, and extratropical surface albedo perturbations. The thin dashed lines depict the benchmarks for compensation mechanisms defined by Eq. (4). The asymmetry is calculated as the difference between the bright surface $\mathrm{NH}$ and the dark surface $\mathrm{SH}$. The hemispheric asymmetry is further decomposed into (b) tropical $\left(0^{\circ}-30^{\circ} \mathrm{N}\right.$ minus $\left.0^{\circ}-30^{\circ} \mathrm{S}\right)$ and (c) extratropical $\left(30^{\circ}-90^{\circ} \mathrm{N}\right.$ minus $\left.30^{\circ}-90^{\circ} \mathrm{S}\right)$ asymmetries. All simulations use the TNT convection scheme and a 50-m slab ocean. Solid lines are drawn to guide the eye.

imposed hemispheric asymmetries in the clear-sky reflection. For the majority of surface albedo perturbations, the hemisphere with larger clear-sky reflection has a smaller all-sky reflection, which indicates that the hemispheric asymmetry in the all-sky reflection is opposite to that seen in clear skies. The overcompensation is reflected by the fact that for small clear-sky asymmetries, the hemispheric all-sky asymmetry successively decreases. The change from a negative to a positive slope for clear-sky asymmetries larger than $8 \mathrm{~W} \mathrm{~m}^{-2}$ ensures the existence of a state wherein the hemispheric all-sky asymmetry vanishes, despite a large hemispheric clear-sky asymmetry.
Asymmetries in tropical cloud cover explain the (over)compensation (Fig. 4). Tropical cloud cover strongly increases in the dark surface hemisphere and decreases in the bright surface hemisphere. For small changes in surface albedo, the cloud cover change is so strong that the hemispheric all-sky asymmetry decreases with increasing hemispheric clear-sky asymmetry. The tropical cloud cover asymmetry saturates for hemispheric clear-sky asymmetries larger than about $8 \mathrm{~W} \mathrm{~m}^{-2}$ (Fig. 4b), coinciding with the negative minimum of the hemispheric all-sky asymmetry and the change of slopes in Fig. 3a. Shifts of the centroid of high tropical clouds away from the equator into the dark surface hemisphere
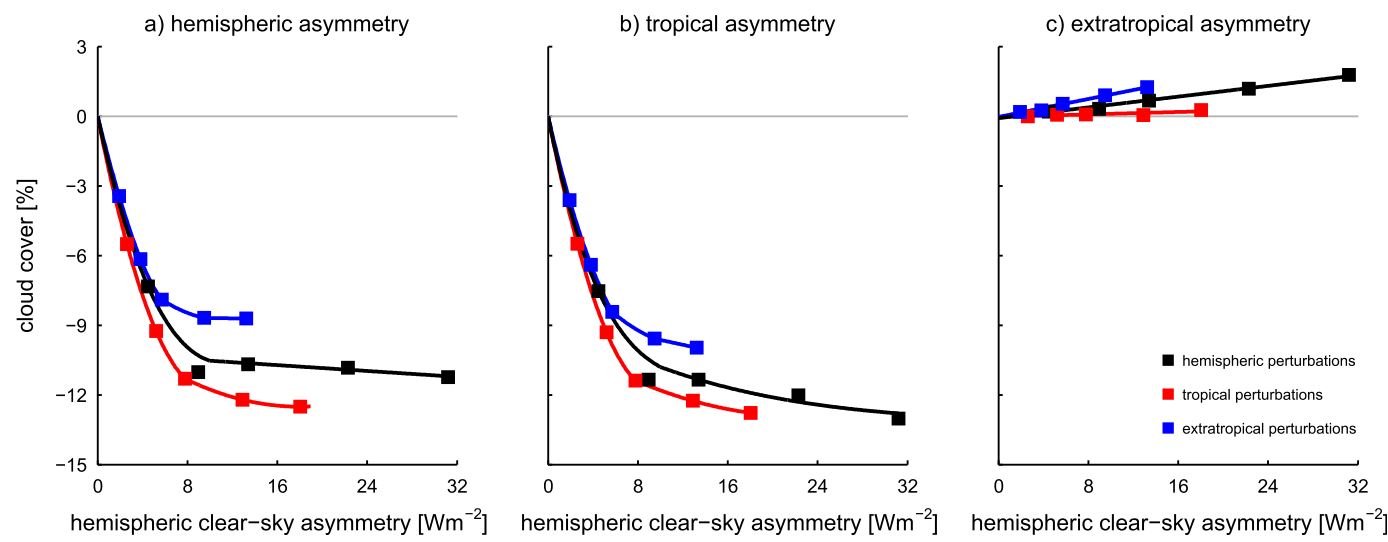

FIG. 4. (a) Hemispheric asymmetry in cloud cover in dependence of the hemispheric asymmetry in the clear-sky reflection for hemispheric, tropical, and extratropical surface albedo perturbations. The asymmetry is calculated as the cloud cover difference between the bright surface $\mathrm{NH}$ and the dark surface SH. The hemispheric asymmetry is further decomposed into (b) tropical $\left(0^{\circ}-30^{\circ} \mathrm{N}\right.$ minus $\left.0^{\circ}-30^{\circ} \mathrm{S}\right)$ and $(\mathrm{c})$ extratropical $\left(30^{\circ}-90^{\circ} \mathrm{N}\right.$ minus $\left.30^{\circ}-90^{\circ} \mathrm{S}\right)$ asymmetries. All simulations use the TNT convection scheme and a 50-m slab ocean. Solid lines are drawn to guide the eye. 
a) surface albedo [\%]
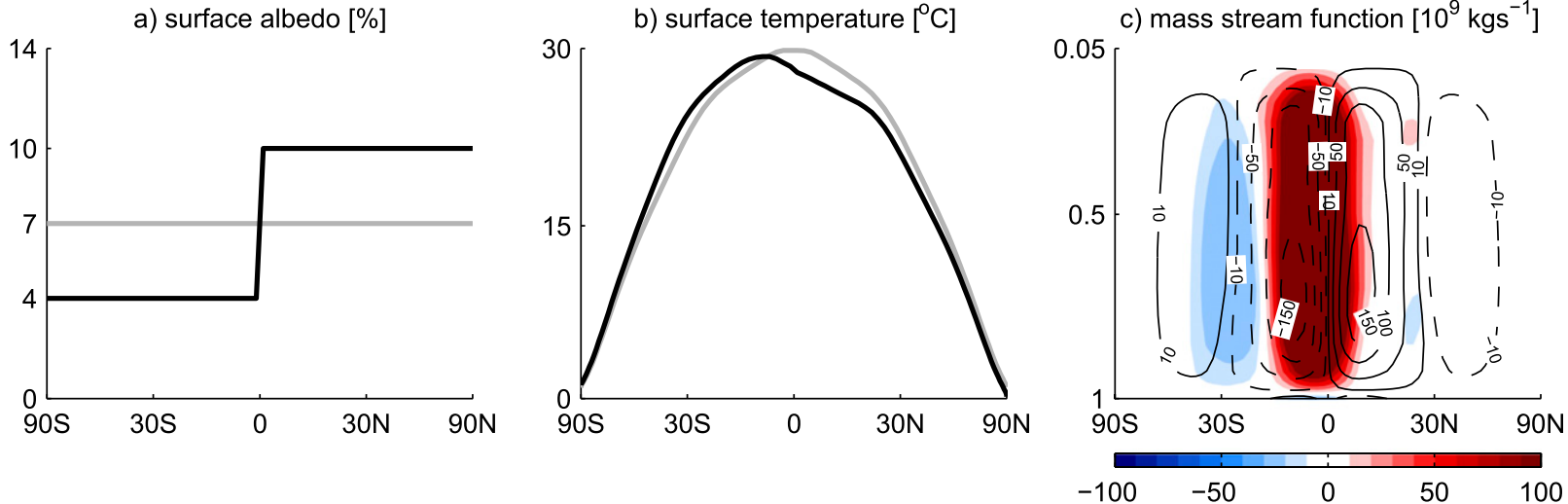

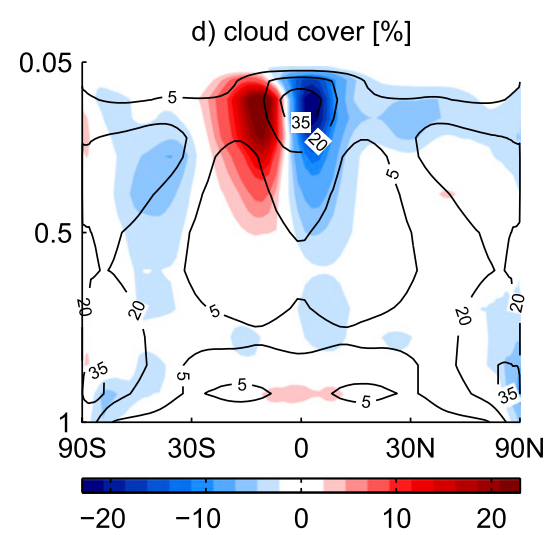

e) reflected shortwave irradiance $\left[\mathrm{Wm}^{-2}\right]$

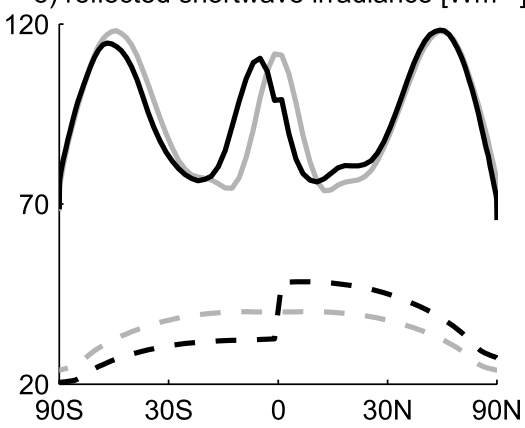

f) outgoing longwave irradiance $\left[\mathrm{Wm}^{-2}\right]$

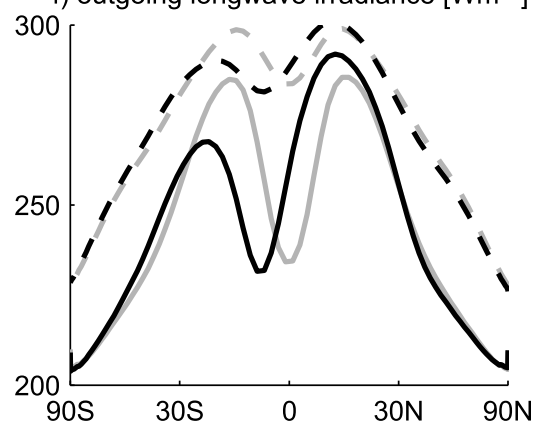

FIG. 5. (a)-(f) Annual-mean zonal-mean comparison of the control climate with globally uniform ocean albedo of $7 \%$ and a perturbed climate with a hemispheric surface albedo perturbation of $3 \%$. In (a),(b),(e) and (f), the control climate is in gray, the perturbed climate in black. (c),(d) Latitude-pressure plots with the pressure given as fraction of the surface pressure. The contour lines in (c) and (d) show the control climate while the colored contours depict the difference between the perturbed and the control climate (perturbed minus control). In (e) and (f), solid lines correspond to all-sky and dashed lines to clear-sky irradiances at TOA. Both simulations use the TNT convection scheme and a 50-m slab ocean.

(i.e., the hemisphere with low clear-sky reflection) are the primary source of the tropical cloud cover asymmetries. In the following section, we show that such tropical cloud shifts follow from the response of the atmospheric circulation to the imposed hemispheric clear-sky asymmetry.

\section{A tropical compensation mechanism: The ITCZ and high tropical clouds shift into the dark surface hemisphere}

Absorption of shortwave irradiance is the ultimate source of energy for the surface. One therefore expects that the surface albedo-induced hemispheric asymmetry in the clear-sky reflection causes an annual-mean hemispheric asymmetry in temperature and hence surface moist static energy: the dark surface hemisphere with small clear-sky reflection should warm, whereas the bright surface hemisphere with high clear-sky reflection should cool compared to the control climate.
Figures $5 \mathrm{a}$ and $5 \mathrm{~b}$ exemplify this for a simulation with a hemispheric surface albedo perturbation of $3 \%$.

The shift of the surface temperature maximum into the dark surface hemisphere has a profound effect on the annual-mean tropical circulation. The maximum of the surface moist static energy, and with it the location of deep convection and the ITCZ, move into the dark surface hemisphere. An anomalous Hadley circulation emerges with cross-equatorial upper-level flow from the dark into the bright surface hemisphere (Fig. 5c). The shift of the ITCZ into the dark surface hemisphere entails a shift of high tropical clouds that form in the convective outflow region (Fig. 5d) and thereby a shift of the tropical maximum in the all-sky reflection (Fig. 5e). These circulation changes explain why the cloud cover increases in the dark surface hemisphere and decreases in the bright surface hemisphere (Fig. 4).

The circulation changes can also be rationalized from the hemispheric asymmetry in the TOA energy budget (Kang et al. 2008, 2009). The surface albedo perturbation 
induces anomalous TOA clear-sky shortwave heating in the dark surface hemisphere and cooling in the bright surface hemisphere. To some extent, the induced hemispheric asymmetry in the TOA energy budget might be compensated locally in each hemisphere by changes in the other budget components. As described by Kang et al. (2009), however, a purely local compensation is hindered by the meridional energy redistribution of the atmospheric circulation and the fact that the free tropical troposphere cannot sustain large temperature gradients due to the small Coriolis parameter (Sobel et al. 2001). As a result, the hemispheric asymmetry in the TOA energy budget necessitates a cross-equatorial energy transport from the dark surface hemisphere into the bright surface hemisphere. This transport has to be achieved through the anomalous Hadley circulation and the shift of the ITCZ into the dark surface hemisphere, again because temperature gradients in the free tropical troposphere are small. In fact, ITCZ shifts in response to hemispheric asymmetries in the TOA energy budget are a common feature of climate models as is discussed in section 8 .

The tropical cloud shift compensates the hemispheric asymmetry in the clear-sky reflection, although this compensation is not exact. Indeed, the shift is so strong as to overcompensate the imposed hemispheric asymmetry in the clear-sky reflection. Because of the overcompensation, the bright surface hemisphere absorbs more shortwave irradiance than the dark surface hemisphere. This seems to contradict the requirement of cross-equatorial energy transport into the bright surface hemisphere. However, the apparent contradiction is resolved by the fact that the tropical cloud shift also creates a strong hemispheric asymmetry in the outgoing longwave irradiance (OLR). Despite being colder, the bright surface hemisphere emits more OLR than the dark surface hemisphere, and this allows the crossequatorial energy transport to be directed into the bright surface hemisphere.

The ITCZ shift is an increasing, but nonlinear, function of the hemispheric asymmetry in the clear-sky reflection (Fig. 6). ${ }^{3}$ This behavior is independent of where the surface albedo is perturbed, which explains why the tropical cloud cover asymmetry and the hemispheric asymmetry in the all-sky reflection are largely insensitive to the location of the surface albedo perturbation (Figs. 3 and 4). The ITCZ shifts are more pronounced

\footnotetext{
${ }^{3}$ Throughout the paper, we calculate the annual-mean ITCZ position as the average of its monthly positions, which we define as the precipitation centroids between $30^{\circ} \mathrm{N}$ and $30^{\circ} \mathrm{S}$. We have also used other definitions such as the latitude of maximum zonal-mean precipitation or vertical mass flux and found no sensitivity of the results with respect to the ITCZ definition.
}

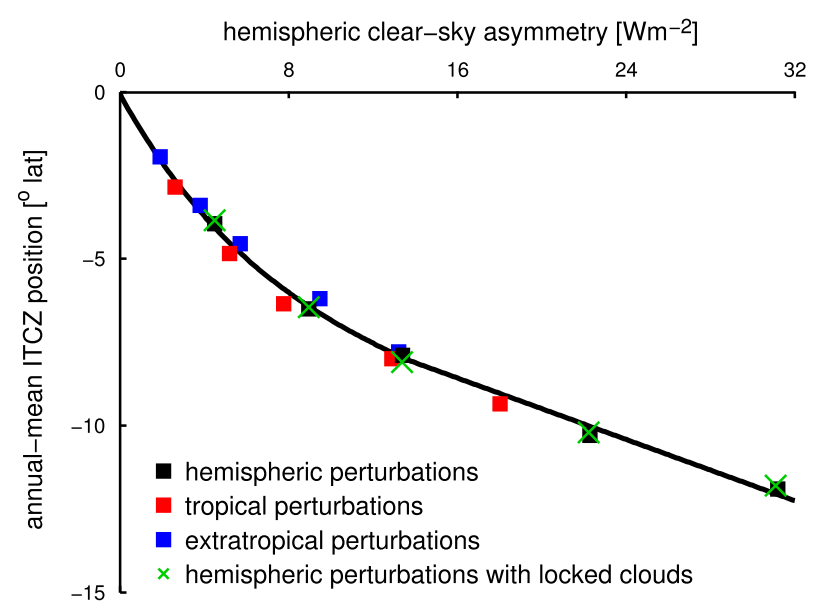

FIG. 6. Annual-mean ITCZ position in dependence of the hemispheric asymmetry in the clear-sky reflection for hemispheric, tropical, and extratropical surface albedo perturbations. All simulations use the TNT convection scheme and a 50-m slab ocean. Cloud-radiative feedbacks do not affect the ITCZ shift for the TNT convection scheme as is illustrated by simulations with locked clouds and hemispheric perturbations. The black line is drawn to guide the eye.

for hemispheric clear-sky asymmetries below $8 \mathrm{~W} \mathrm{~m}^{-2}$ [slope of $0.9^{\circ}\left(\mathrm{W} \mathrm{m}^{-2}\right)^{-1}$ ] but less pronounced for larger asymmetries [slope of $0.2^{\circ}\left(\mathrm{W} \mathrm{m}^{-2}\right)^{-1}$ ]. A likely reason for the decreased slope for larger surface albedo perturbations is that the ITCZ successively shifts into regions of stronger meridional surface temperature gradients and seasonality, both of which are expected to stabilize the ITCZ against annual-mean shifts. While we do not further pursue the influence of the meridional surface temperature gradients, we will come back to how seasonality controls annual-mean ITCZ shifts in section 7.

Similar to the ITCZ shift, the tropical cloud cover asymmetry depends nonlinearly on the hemispheric asymmetry in the clear-sky reflection (Fig. 4b). To some extent, the nonlinearity in the tropical cloud cover asymmetry is a geometric effect. For large ITCZ shifts, all high tropical clouds have been permanently displaced into the dark surface hemisphere. As a result, further shifts of the ITCZ no longer affect the tropical cloud cover asymmetry and, if anything, increase the hemispheric asymmetry in the all-sky reflection as tropical clouds move deeper into the dark surface hemisphere where they find less incoming solar irradiance to reflect. On the other hand, the coupling between shifts of the ITCZ and tropical clouds for smaller perturbations and the fact that the ITCZ shift is more pronounced for smaller perturbations raise the question to what extent clouds affect the magnitude of the ITCZ shift. This question is taken up in the next section. 


\section{Do cloud-radiative feedbacks affect the magnitude of the ITCZ shift?}

The cloud shift and overcompensation of hemispheric asymmetries in the clear-sky reflection result from the strong shift of the ITCZ into the dark surface hemisphere. Previous modeling studies have found that clouds, or more precisely cloud-radiative feedbacks, amplify ITCZ shifts (Kang et al. 2008, 2009) through their effect on the hemispheric asymmetry in the TOA energy budget. In particular, Cvijanovic et al. (2013) found that tropical cloud-radiative feedbacks amplify the hemispheric asymmetry in the TOA energy budget and thus the ITCZ shift. Motivated by these studies, this section explores to what extent cloud changes and associated cloud-radiative feedbacks are essential to the strong ITCZ shift. To this end, we first conduct simulations with locked clouds to study the role of cloudradiative feedbacks on the ITCZ shift. We then interpret the results of these locked cloud simulations by diagnosing the effect of clouds on the hemispheric asymmetry in the TOA energy budget and the crossequatorial energy transport.

We use the cloud-locking technique to quantify the degree to which cloud-radiative feedbacks amplify or dampen the ITCZ shift (cf. Kang et al. 2008, 2009; Zhang et al. 2010; Langen et al. 2012; Mauritsen et al. 2013). The cloud-radiative feedback is disabled by storing the cloud-radiative properties from the symmetric control simulation and prescribing (or locking) them in the perturbed simulations. Specifically, cloud cover, cloud liquid water, and cloud ice are diagnosed from 15 years of the equilibrated control simulation at each 2-hourly call of the radiation calculation. In the perturbed simulations with locked clouds, the radiation is then calculated based on the control instead of the actual clouds. Locking clouds makes the model's radiation inconsistent with its predicted distribution of clouds but does not introduce any spurious energy sinks or sources; the model conserves energy with the same accuracy as in simulations with free clouds (see section 2). Further details on the cloud-locking technique are given in Mauritsen et al. (2013). If cloud-radiative feedbacks amplified the ITCZ shift, simulations with locked clouds would exhibit smaller ITCZ shifts than those with free clouds, and vice versa if cloud-radiative feedbacks dampened the ITCZ shift.

We lock clouds in simulations that apply the full range of hemispheric surface albedo perturbations and use TNT convection and a 50-m slab ocean (section 4). The ITCZ shift in simulations with locked clouds is the same as in simulations with free clouds; the maximum relative difference is smaller than 5\% (green crosses in Fig. 6).
Cloud-radiative feedbacks hence do not impact the ITCZ shift. In particular, the initially strong ITCZ shift that leads to the overcompensation is not the result of a strong positive cloud-radiative feedback.

The ITCZ position is correlated with the tropical asymmetry in surface temperature (e.g., Chiang and Friedman 2012; Donohoe et al. 2013b), and changes in tropical surface temperature have been shown to be necessary for shifting the ITCZ (Cvijanovic and Chiang 2013). One might therefore expect that the cloudradiative feedbacks associated with the shift of high tropical clouds damp the ITCZ shift, contrary to what is found in the locked cloud simulations. Such an expectation would build on the fact that the cloud shift reduces the shortwave surface downward irradiance in the tropics of the dark surface hemisphere and increases it in the tropics of the bright surface hemisphere. Longwave surface downward irradiance, which mainly originates from the lower atmosphere, is not substantially affected by the cloud shift. The resulting tropical asymmetry in net surface downward irradiance, however, does not lead to changes in surface temperatures because changes in evaporation largely balance changes in the surface energy input. The effect of cloud-radiative feedbacks on the ITCZ shift thus cannot be adequately inferred from cloud-induced changes in the surface downward irradiance.

Instead, the effect of cloud-radiative feedbacks on the ITCZ shift must be approached from a consideration of their effect on the hemispheric asymmetry in the TOA energy budget, which because the ocean transport is held fixed must match the cross-equatorial transport of energy by the atmosphere (e.g., Kang et al. 2008, 2009; Cvijanovic and Chiang 2013). The consideration rests on the strong relationship between the cross-equatorial atmospheric energy transport and the ITCZ location (Donohoe et al. 2013b). The cross-equatorial atmospheric energy transport is calculated from the hemispheric asymmetry in the TOA all-sky irradiances:

$$
F=\Delta R+\Delta L .
$$

Here, $\Delta$ is the hemispheric asymmetry [defined as the Northern Hemisphere mean minus the Southern Hemisphere mean; cf. Eq. (3)]; $R$ is the reflected shortwave irradiance, and $L$ is the outgoing longwave irradiance. The terms $R$ and $L$ are defined as positive upward; a positive $F$ means northward transport. To simplify the notation, we omit the constant geometrical factor that converts the irradiances in watts per meter squared to the transport in petawatts. To elucidate the effect of cloud-radiative feedbacks, the transport is rewritten as 
$F=\Delta R_{\text {sfc }}+R_{\text {atm }}^{\text {cloud }}+\Delta R_{\mathrm{atm}}^{\text {water-vapor }}+\Delta L_{\text {clear }}+\Delta \mathrm{LCRE}$.

Here, the longwave all-sky irradiance is decomposed into clear-sky irradiances $L_{\text {clear }}$ and cloud-radiative effects (LCRE). Because the hemispheric TOA energy budget is perturbed via changes in surface albedo, cloudmasking effects (Soden et al. 2004) devaluate such a decomposition for the reflected shortwave irradiance. Instead, following Hwang and Frierson (2010) the approximate partial radiative perturbation method of Taylor et al. (2007) is used to decompose $\Delta R$ into contributions from the surface albedo perturbation $\Delta R_{\mathrm{sfc}}$, clouds $\Delta R_{\text {atm }}^{\text {cloud }}$, and noncloud atmospheric components, which in our simulations are limited to water vapor changes $\Delta R_{\mathrm{atm}}^{\text {water-vapor }}$. Note that $\Delta R_{\mathrm{atm}}^{\text {cloud }}$ is different from $\Delta R_{\text {cloud }}$ defined in section 3 .

Figure 7 (top) depicts the decomposition of the crossequatorial energy transport according to Eq. (6). Most of the transport is explained by the surface albedo perturbation. Clear-sky longwave changes slightly amplify the transport, especially for small surface albedo perturbations because of the shift of water vapor into the dark surface hemisphere (Yoshimori and Broccoli 2009; Frierson and Hwang 2012). The net contribution of clouds is nearly zero, and this is also seen in the locked simulations in which clouds do not contribute to the transport (Fig. 7, bottom). In the free simulations, the near-zero cloud contribution results from an almost perfect compensation between strong dampening shortwave and amplifying longwave cloud effects. Compensation between the shortwave and longwave cloud contributions is not surprising because the shift of high tropical clouds at the same time increases the all-sky reflection but decreases the outgoing longwave radiation in the dark surface hemisphere, and vice versa for the bright surface hemisphere (Pierrehumbert 1995). The fact that the compensation is perfect in the TNT scheme considered here is somewhat expected as the high tropical clouds generated by this scheme show a near-zero net TOA cloud-radiative effect in the control simulation. In section 7 we will show, however, that the effect of clouds on the ITCZ shift depends on the convection scheme as the latter influences the net TOA cloud-radiative effect of high tropical clouds.

\section{Influence of convection scheme and slab ocean depth on degree of compensation and ITCZ shift}

In this section, we study to what extent the overcompensation, or more generally the degree of compensation, depends on the choice of the convection scheme
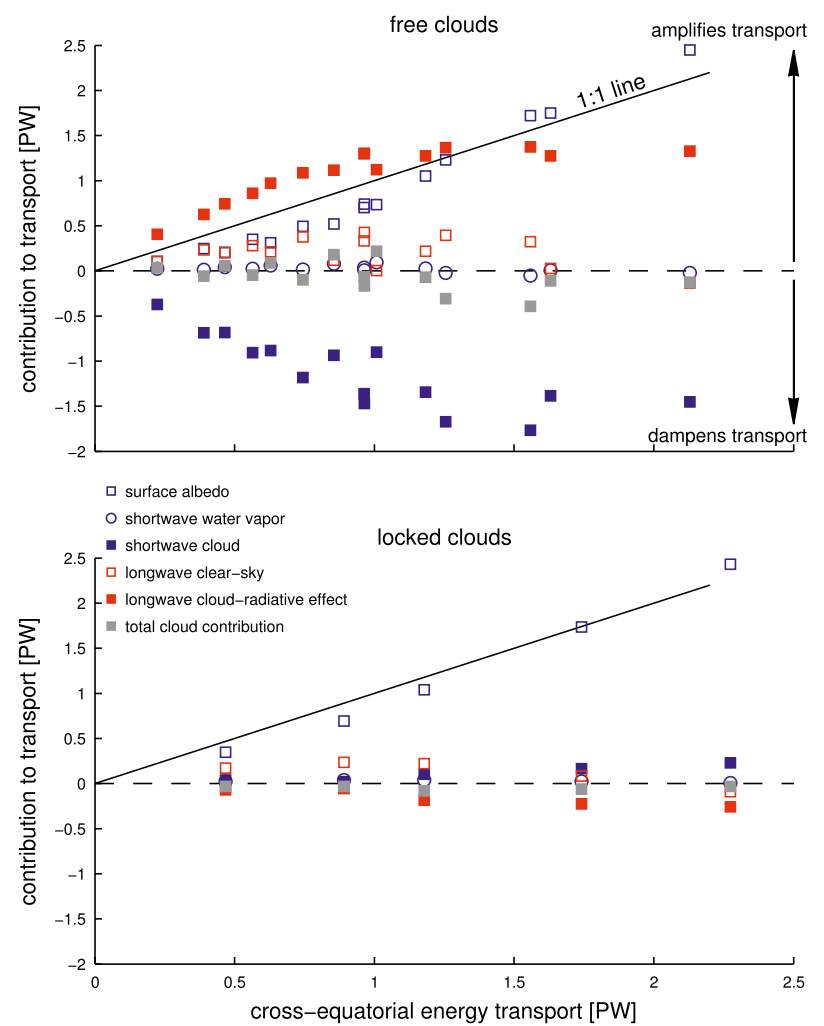

FIG. 7. Decomposition of the cross-equatorial atmospheric energy transport in simulation with (top) free and (bottom) locked clouds. Using Eq. (6), the transport is decomposed into shortwave contributions (blue) from surface albedo, water vapor, and clouds and into longwave contributions (red) from clear-sky longwave irradiance and the longwave cloud-radiative effect. The total (shortwave plus longwave) contribution from clouds is in gray. All simulations use the TNT convection scheme and a 50-m slab ocean. For free clouds, hemispheric, tropical, and extratropical surface albedo perturbations are shown. For locked clouds, only hemispheric perturbations are used.

and the slab ocean depth. To this end, we perform simulations with ECHAM6's standard TNT convection scheme replaced by the TTT scheme [see section 2 and Möbis and Stevens (2012)] and/or the depth of the slab ocean reduced from 50 to $30 \mathrm{~m}$. As further discussed below, the two convection schemes differ substantially in their net TOA cloud-radiative effect of high tropical clouds, which will have a decisive effect on how clouds affect the ITCZ shift. Reducing the slab ocean depth is an approximate way to account for the effect of land on the surface heat capacity. Because the overcompensation occurs irrespective of the location of the surface albedo perturbation, only hemispheric perturbations are applied. The convection scheme and the slab ocean depth affect the tropical climate of the symmetric control simulations, offering the possibility to relate differences in the degree of 
compensation to differences in the tropical climate of the control simulations.

The convection scheme and the depth of the slab ocean impact the tropical climate of the control simulations. Compared to the TNT scheme, the TTT scheme results in higher equatorial temperatures and a steeper meridional temperature gradient (Fig. 8, top). When a 50-m slab ocean is used, both convection schemes show a single ITCZ, with annual-mean precipitation peaking at the equator (Fig. 8, middle). The equatorial precipitation maximum is higher for the TTT scheme as a result of a stronger Hadley circulation and higher humidity in the tropical planetary boundary layer. Interestingly, the equatorial precipitation maximum is also sharper and the ITCZ exhibits less seasonal migrations for the TTT scheme compared to the TNT scheme (Table 1), which is in contrast to aquaplanet simulations with fixed sea surface temperatures in which the TTT scheme tends to generate a double ITCZ more easily than the TNT scheme and distributes the precipitation over a larger tropical area (Möbis and Stevens 2012). In simulations with a 30-m slab ocean, the reduced surface heat capacity allows stronger seasonal migrations of the ITCZ (Table 1). This leads to less pronounced equatorial temperature maxima in the $30-\mathrm{m}$ simulations compared to the $50-\mathrm{m}$ simulations and to hints of a double ITCZ as a result of seasonal off-equatorial precipitation. In terms of cloud cover, the TTT scheme generates a more pronounced peak in equatorial cloud cover than the TNT scheme. Moreover, a shallower slab ocean yields a less pronounced cloud cover peak as a result of the increased seasonal cycle (Fig. 8, bottom). These modulations of the tropical climate with the slab ocean depth are expected and consistent with Donohoe et al. (2013a).

Clouds compensate hemispheric differences in the clear-sky reflection independent of whether we use the TNT or TTT scheme or a shallow or deep slab ocean: the hemispheric asymmetry in the all-sky reflection never exceeds the benchmark (Fig. 9a). A decomposition of the hemispheric asymmetry into tropical and extratropical asymmetries analogous to Fig. 3 shows that the compensation results entirely from the tropics. The extratropical asymmetry is slightly positive and independent of the convection scheme and slab ocean depth. Figure 9a therefore reflects essentially the tropical asymmetry.

The strength of the tropical compensation mechanism is sensitive to the convection scheme and the slab ocean depth. For a given slab ocean depth, the TTT scheme produces a stronger compensation than the TNT scheme for small hemispheric asymmetries in the clear-sky reflection but a weaker compensation for
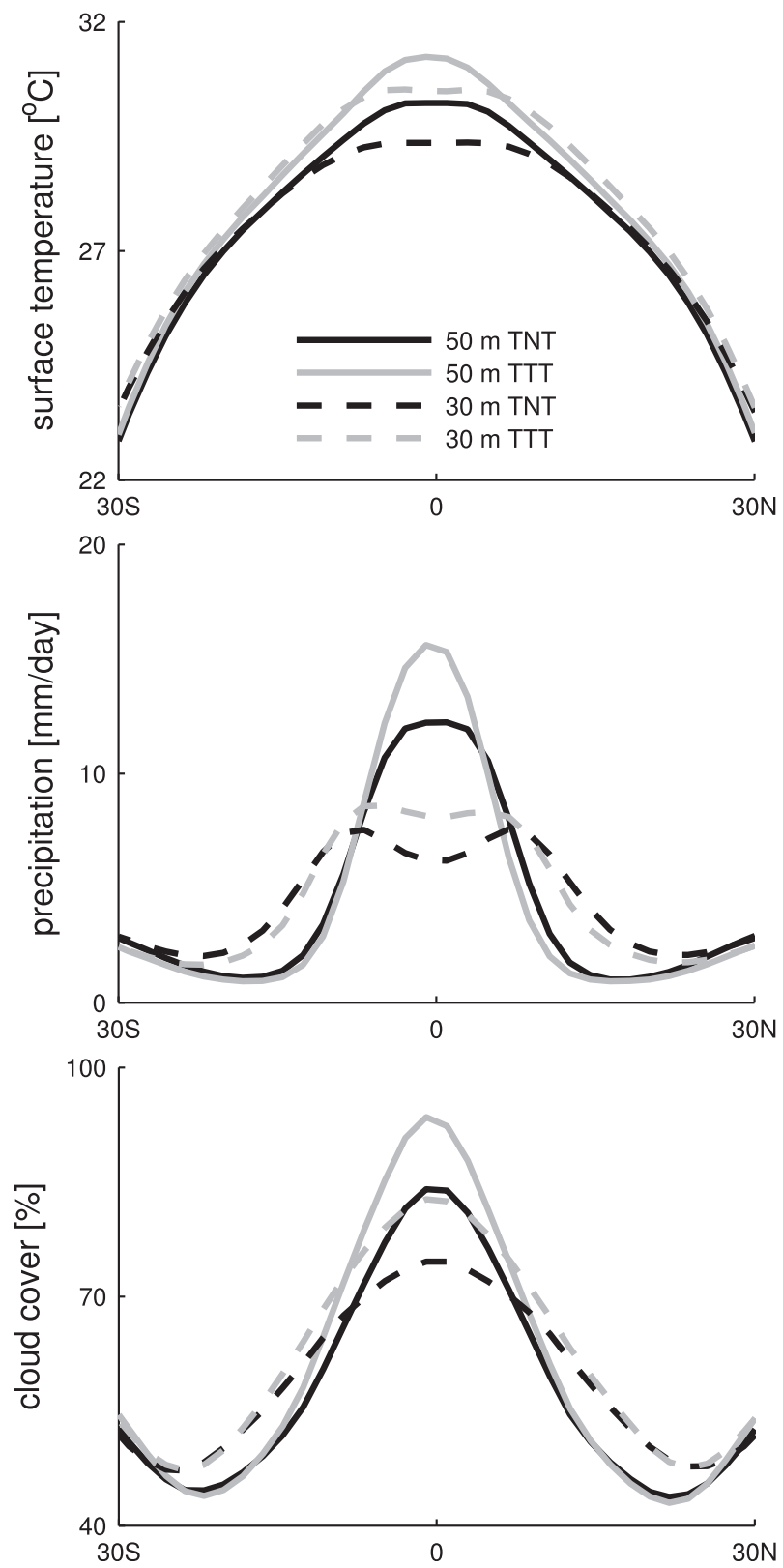

FIG. 8. Annual-mean zonal-mean (top) surface temperature, (middle) precipitation, and (bottom) cloud cover in the symmetric control simulations with a globally uniform surface albedo of $7 \%$. The simulations differ in the convection scheme (TNT or TTT) and slab ocean depth (30 or $50 \mathrm{~m})$.

large asymmetries. Reducing the slab ocean depth weakens the tropical compensation mechanism. While both convection schemes exhibit overcompensation for a $50-\mathrm{m}$ slab ocean, there is no overcompensation when the slab ocean depth is decreased to $30 \mathrm{~m}$. Instead, the shallow slab ocean simulations show a range of hemispheric clear-sky asymmetries over which the hemispheric all-sky asymmetry is constant and hence 
TABLE 1. Simulations with a hemispheric surface albedo asymmetry of $1 \%$ (NH surface albedo of $8 \%$, SH surface albedo of $6 \%$ ) leading to a $4.5 \mathrm{~W} \mathrm{~m}^{-2}$ hemispheric asymmetry in the clear-sky reflection. The table summarizes the influence of the convection scheme and slab ocean depth on the tropical compensation mechanism and the annual-mean ITCZ shift. Here $\Delta R$ is the hemispheric asymmetry in the all-sky reflection. The magnitude of the seasonal cycle is measured as the maximum poleward seasonal migration of the ITCZ in the control simulations. The annual-mean ITCZ shift in response to the surface albedo perturbation is given for simulations with enabled and disabled cloud-radiative feedbacks (marked as free and locked clouds). The effect of cloud-radiative feedbacks on the cross-equatorial atmospheric energy transport is calculated by Eq. (6). Values in parentheses indicate the percentage of the total transport that is attributed to clouds.

\begin{tabular}{|c|c|c|c|c|}
\hline & \multicolumn{2}{|c|}{ TNT convection } & \multicolumn{2}{|c|}{ TTT convection } \\
\hline & 30-m ocean & 50-m ocean & 30-m ocean & 50-m ocean \\
\hline$\Delta R\left(\mathrm{~W} \mathrm{~m}^{-2}\right)$ & 1.5 & -4.4 & 0.0 & -6.2 \\
\hline Magnitude of seasonal ITCZ migration $\left({ }^{\circ}\right.$ lat $)$ & 10.1 & 5.7 & 9.5 & 4.9 \\
\hline ITCZ shift with free clouds $\left({ }^{\circ}\right.$ lat $)$ & -1.8 & -4.0 & -3.3 & -5.0 \\
\hline ITCZ shift with locked clouds ( ${ }^{\circ}$ lat $)$ & -1.8 & -4.0 & -1.1 & -1.9 \\
\hline Cloud contribution to equatorial energy transport $(\mathrm{PW})$ & $<0.1(7 \%)$ & $0.1(5 \%)$ & $0.2(30 \%)$ & $0.5(40 \%)$ \\
\hline
\end{tabular}

insensitive to a change of the hemispheric clear-sky asymmetry.

Differences in the degree of compensation are explained by differences in the hemispheric cloud cover asymmetry. As for the all-sky reflection, the cloud changes largely stem from the tropics, so the hemispheric cloud cover asymmetry shown in Fig. 9 b nearly equals the tropical asymmetry (not shown). On the one hand, differences in the hemispheric cloud cover asymmetry result from differences in the annual-mean distribution of tropical clouds. This is because the same ITCZ shift results in a larger tropical cloud shift when the tropical cloud cover maximum is more pronounced. On the other hand, differences in the hemispheric cloud cover asymmetry are closely linked to the magnitude of the ITCZ shift: the stronger the ITCZ shift, the stronger the cloud shift and hence the compensation. Consistent with this, the degree of compensation scales with the magnitude of the ITCZ shift (cf. Figs. 9a,c). This implies that in order to understand differences in the degree of compensation, we need to understand why the ITCZ shift depends on the convection scheme and the slab ocean depth.

To investigate to what extent cloud-radiative feedbacks contribute to the sensitivity, we lock clouds in the simulations with a hemispheric surface albedo perturbation of $1 \%$ using the feedback-locking technique of section 5 . Consistent with section 5 , cloud-radiative feedbacks do not affect the ITCZ shift for simulations with the TNT convection scheme for both a deep and a shallow slab ocean (Fig. 10, left; Table 1). In contrast, cloud-radiative feedbacks amplify the ITCZ shift in
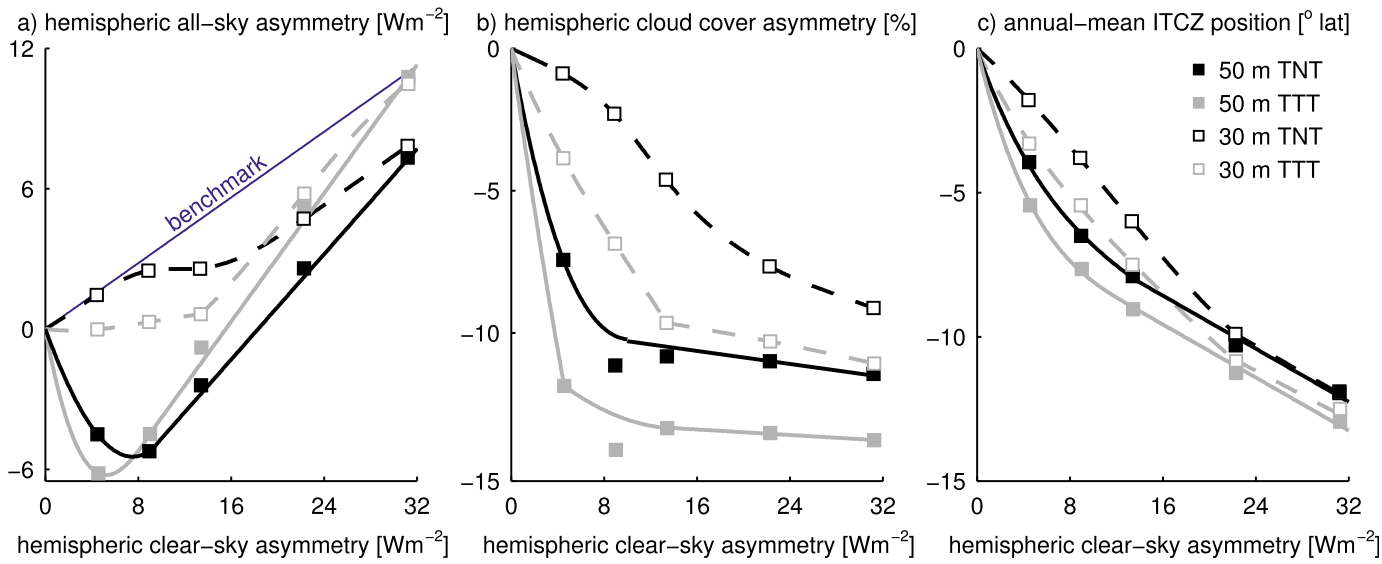

FIG. 9. Influence of the convection scheme and slab ocean depth on the strength of the tropical compensation mechanisms and the ITCZ shift. The hemispheric asymmetries in the (a) all-sky reflection and (b) cloud cover as well as (c) the annual-mean ITCZ position are shown in dependence of the hemispheric asymmetry in the clear-sky reflection. All simulations use hemispheric surface albedo perturbations. Lines are drawn to guide the eye. The blue line in (a) depicts the benchmark for the 50-m TNT simulation. Only this benchmark is shown because the benchmarks are nearly independent of the convection scheme and the slab ocean depth. 

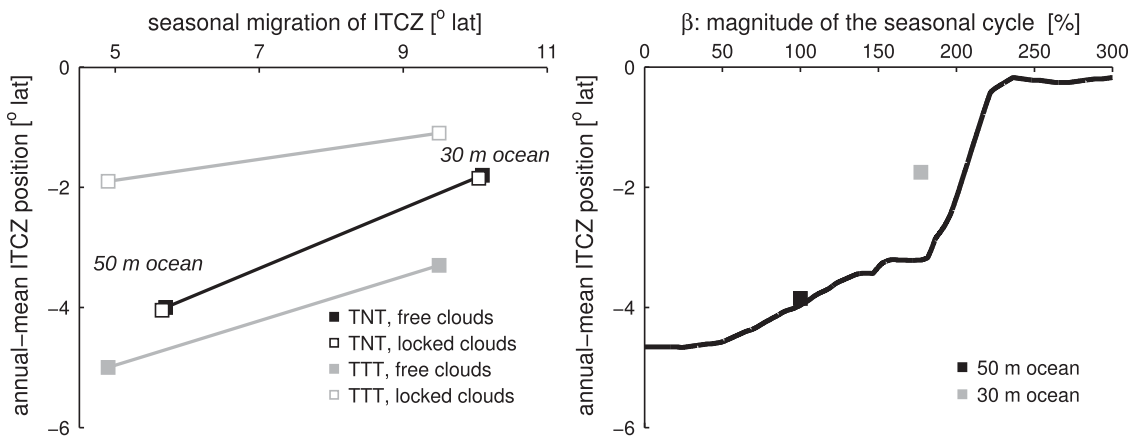

FIG. 10. Influence of the strength of the seasonal cycle on the annual-mean ITCZ shift. (left) Seasonal migration of the ITCZ in the control simulations plotted against the annual-mean ITCZ shift in response to a hemispheric surface albedo perturbation of $1 \%$ for simulations with free and locked clouds. (right) The conceptual model using Eq. (9). See text for details. For reference, the squares show the annual-mean ITCZ position of the TNT simulations for a deep and shallow slab ocean and a hemispheric surface albedo perturbation of $1 \%$ (cf. Table 1).

simulations with the TTT convection scheme. In these simulations, the ITCZ shift is only one-third when clouds are locked. The effect of cloud-radiative feedbacks on ITCZ shift is correctly predicted by their effect on the cross-equatorial atmospheric energy transport [Eq. (6) and Table 1], which supports the use of the TOA energy budget in attribution studies of shifts of the ITCZ and tropical rainbelt (e.g., Frierson and Hwang 2012; Cvijanovic and Chiang 2013).

Differences in the effect of cloud-radiative feedbacks on the ITCZ shift between the TNT and TTT convection schemes (zero for TNT and strong amplification for TTT) are caused by differences in the net TOA cloudradiative effect associated with the two schemes. In the TTT scheme, convection is more adiabatic and penetrates deeper into the troposphere (Möbis and Stevens 2012), leading to a larger longwave cloud-radiative effect of high tropical clouds than in the TNT scheme. The shift of high tropical clouds therefore demands an additional cross-equatorial energy transport and ITCZ shift for the TTT scheme, compared to the near-zero effect for the TNT scheme. Overall, we find that cloudradiative feedbacks contribute to the sensitivity of the ITCZ shift to the convection scheme. However, because the ITCZ shift differs substantially between simulations with the TNT and TTT schemes even when clouds are locked, cloud-radiative feedbacks alone do not explain the sensitivity. Future work is needed to settle this issue.

The slab ocean depth systematically influences the ITCZ shift in all simulations. In particular, simulations with locked clouds show the same sensitivity to the slab ocean depth as simulations with free clouds (Fig. 10, left). Therefore, differences in clouds caused by differences in the slab ocean depth do not explain the sensitivity. Instead, we argue below that the sensitivity results from the effect of the slab ocean depth on the seasonality. A reduced slab ocean depth increases the magnitude of the seasonal cycle and the seasonal ITCZ migrations, and this strongly impacts the annual-mean ITCZ shift: the larger the seasonal cycle in the symmetric control simulation, the smaller the annual-mean ITCZ shift in response to a given surface albedo perturbation (Table 1; Fig. 10, left). This suggests that a strong seasonal cycle stabilizes the ITCZ against annual-mean meridional shifts.

The stabilizing effect of a strong seasonal cycle results from a competition between the seasonal cycle and the perturbation. The following model illustrates this. Based on the strong relationship between surface moist static energy and sea surface temperature, we assume that the ITCZ is collocated with the surface temperature maximum. The monthly-mean surface temperature of the control simulation $T$ can be written as

$$
T(\varphi, t)=\bar{T}(\varphi)+\hat{T}(\varphi, t)
$$

where $\varphi$ is latitude, $t=1, \ldots, 12$ is the month of the year, and the overbar and hat denote the annual average and the seasonal cycle, respectively. The surface albedo perturbation leads to a change in surface temperature $\delta T(\varphi, t)$, and the surface temperature of the perturbed simulation is

$T^{\prime}(\varphi, t)=T(\varphi, t)+\delta T(\varphi, t)=\bar{T}(\varphi)+\hat{T}(\varphi, t)+\delta T(\varphi, t)$.

The monthly-mean surface temperature maximum defines the monthly-mean position of the ITCZ. If the perturbation is much stronger than the seasonal cycle 
$(\delta T \gg \hat{T})$, the monthly-mean ITCZ position is mainly determined by the perturbation. In contrast, if the seasonal cycle is much stronger than the perturbation $(\hat{T} \gg \delta T)$, the monthly-mean ITCZ position hardly feels the perturbation. Instead the monthly-mean ITCZ position of the perturbed simulation is close to that of the control simulation, which implies that the annualmean ITCZ positions of the perturbed and control simulation are also close and that the annual-mean ITCZ shift is small.

To further study the competition between the seasonal cycle and the perturbation in the model, we diagnose $\bar{T}$ and $\hat{T}$ from the control simulation. The term $\delta T$ is taken from the simulation with a hemispheric surface albedo perturbation of $1 \%$ (NH surface albedo of $8 \%$, SH surface albedo of $6 \%$ ). Both simulations use the TNT convection scheme and a 50-m slab ocean. The surface temperature maximum and ITCZ are collocated during all months in both simulations (not shown), which verifies that the temperature-based definition of the ITCZ position is useful. We vary the magnitude of the seasonal cycle by multiplying $\hat{T}$ with $\beta$, where $\beta$ is some nonnegative real number, to study how the magnitude of the seasonal cycle affects the annual-mean ITCZ shift:

$$
T^{\prime}(\varphi, t ; \beta)=\bar{T}(\varphi)+\beta \hat{T}(\varphi, t)+\delta T(\varphi, t) .
$$

Consistent with the above considerations, a given perturbation leads to a smaller annual-mean ITCZ shift if the seasonal cycle is large, and vice versa (Fig. 10, right). In particular, if the seasonal cycle is much larger than the perturbation, the perturbation yields no annual-mean ITCZ shift at all.

\section{Conclusions}

Motivated by the observed hemispheric symmetry in Earth's albedo (Vonder Haar and Suomi 1971; Ramanathan 1987; Zhang and Rossow 1997; Hatzianastassiou et al. 2004a,b; Voigt et al. 2013), we study to what extent and by which mechanisms clouds compensate hemispheric asymmetries in clear-sky albedo. To this end we perform aquaplanet simulations with the atmospheric general circulation model ECHAM6 coupled to a slab ocean. In these simulations, asymmetries in clear-sky albedo are introduced through surface albedo perturbations. We find that clouds adapt such as to compensate clear-sky albedo asymmetries independent of the location and magnitude of the surface albedo perturbation, a change of the scheme representing atmospheric convection, and a change of the slab ocean depth. The simulations encourage the idea that the climate system prefers asymmetries in albedo to be small and that tropical circulations adjust such as to reduce asymmetries in the absorbed solar irradiance between the hemispheres, although there is no evidence of a mechanism that exactly symmetrizes the hemispheric albedo.

The compensation results from a shift of the ITCZ and tropical clouds into the dark surface hemisphere with low clear-sky albedo. The surface albedo perturbations lead to a warming of the dark surface hemisphere and corresponding cooling of the bright surface hemisphere. They also lead to a surplus of TOA energy input in the dark surface hemisphere and a deficit in the bright surface hemisphere. Both factors cause a shift of the ITCZ into the dark surface hemisphere. ITCZ shifts into the warmed hemisphere are a robust feature of climate models (e.g., Chiang et al. 2003; Broccoli et al. 2006; Kang et al. 2008, 2009; Chiang and Friedman 2012). As ITCZ shifts inevitably cause shifts of tropical clouds, we expect that the tropical compensation mechanism identified here is a robust feature of climate models. This provides confidence that the tropical compensation mechanism indeed operates in the real climate system.

Our study is motivated by the hemispheric symmetry of Earth's albedo. At first sight, the tropical compensation mechanism seems to be at odds with the observed hemispheric symmetry in Earth's albedo because the ITCZ is primarily located north of the equator, that is, in the bright surface hemisphere. However, the results of Hwang and Frierson (2013) suggest that the northern ITCZ position is, at least partly, caused by the bright and widespread clouds of the Southern Hemisphere storm tracks. Adopting this view, the northern ITCZ position follows from the tropical compensation mechanism in response to the hemispheric asymmetries in extratropical clouds. The suggested connection between tropical and extratropical cloud and circulation systems warrants future research.

The strength of the tropical compensation mechanism is sensitive to the representation of atmospheric convection and the slab ocean depth. The sensitivity results directly from the influence of these two factors on the magnitude of the ITCZ shift. We note that Kang et al. $(2008,2009)$ were the first to demonstrate that the convection scheme and its effect on cloud-radiative feedbacks influence the magnitude of the ITCZ shift. However, while the influence of the convection scheme in the simulations of Kang et al. $(2008,2009)$ was mainly related to low-level midlatitude and subtropical clouds, in our simulations the influence follows from the fact that different convection schemes are known to produce different net TOA cloud-radiative effects of high-level tropical clouds within the ITCZ (Bony et al. 2004). This 
highlights the importance of reproducing the correct relationship between cloud-radiative effects and circulation when studying how regional circulations respond to perturbations. The sensitivity of the ITCZ shift to the slab ocean depth, or equivalently the heat capacity of the underlying surface, emerges as a robust feature and is reproduced in a conceptual model. For the same perturbation, a shallow ocean yields smaller ITCZ shifts than a deep ocean. Put differently, large seasonal migrations stabilize the ITCZ against annual-mean shifts, which indicates that monsoonal climates are less prone to annual-mean ITCZ shifts than climates with small seasonal variations. The stabilizing effect of a strong seasonal cycle should be important and potentially visible in model simulations that investigate changes in tropical rainfall distribution in response to increasing greenhouse gas concentrations or hemispherically asymmetric aerosol emissions, in particular because such studies often use slab ocean models (e.g., Yoshimori and Broccoli 2008, 2009; Ming and Ramaswamy 2011; Frierson and Hwang 2012).

Observational proxies support the possibility that the tropical compensation mechanism was active in Earth's past. There is evidence that hemispherically asymmetric changes in high-latitude ice cover were accompanied by shifts of the ITCZ into the hemisphere with reduced ice coverage, which would have led to a compensation of the ice-induced hemispheric asymmetries in clear-sky albedo. For example, Pahnke et al. (2007) reported a southward ITCZ shift during the Last Glacial Maximum, and Holbourn et al. (2010) found evidence for a northward ITCZ shift associated with the inception of Antarctic glaciation. The climate model studies of Chiang et al. (2003) and Chiang and Bitz (2005) support such ice-induced ITCZ shifts. Moreover, while our study investigates clear-sky albedo asymmetries that result from perturbations to the ocean surface albedo, modeling studies on the circulation response to vegetation (McCarthy et al. 2012; Swann et al. 2012) and aerosol (Yoshimori and Broccoli 2008, 2009; Ming and Ramaswamy 2011) perturbations indicate that the compensation mechanism operates for any radiative forcing agent that introduces a clear-sky albedo asymmetry.

Acknowledgments. The authors thank Aaron Donohoe, Benjamin Moebis, two anonymous reviewers, and the editor Dr. John Chiang for their constructive suggestions and substantive insights on an earlier draft of this manuscript. A.V. acknowledges the hospitality of the Laboratoire de Météorologie Dynamique and support from the German Research Foundation under Grant Agreement VO 1765/3-1. This research was supported by the Max Planck Society for the Advancement of
Science and by funding from the European Union, Seventh Framework Program (FP7/20072013) under Grant Agreement 244067. Computing resources were provided by the German Climate Computing Center (DKRZ), Hamburg.

\section{REFERENCES}

Andrews, T., J. M. Gregory, M. J. Webb, and K. E. Taylor, 2012: Forcing, feedbacks and climate sensitivity in CMIP5 coupled atmosphere-ocean climate models. Geophys. Res. Lett., 39, L09712, doi:10.1029/2012GL051607.

Bender, F. A. M., 2011: Planetary albedo in strongly forced climate, as simulated by the CMIP3 models. Theor. Appl. Climatol., 105, 529-535, doi:10.1007/s00704-011-0411-2.

Bony, S., J.-L. Dufresne, H. Le Treut, J.-J. Morcrette, and C. Senior, 2004: On dynamic and thermodynamic components of cloud changes. Climate Dyn., 22, 71-86, doi:10.1007/ s00382-003-0369-6.

— uate climate change feedback processes? J. Climate, 19, 34453482 .

Broccoli, A., K. Dahl, and R. Stouffer, 2006: Response of the ITCZ to Northern Hemisphere cooling. Geophys. Res. Lett., 33, L01702, doi:10.1029/2005GL024546.

Chiang, J. C. H., and C. Bitz, 2005: Influence of high latitude ice cover on the marine intertropical convergence zone. Climate Dyn., 25, 477-496, doi:10.1007/s00382-005-0040-5.

_ , and A. R. Friedman, 2012: Extratropical cooling, interhemispheric thermal gradients, and tropical climate change. Annu. Rev. Earth Planet. Sci., 40, 383-412, doi:10.1146/ annurev-earth-042711-105545.

-, M. Biasutti, and D. S. Battisti, 2003: Sensitivity of the Atlantic intertropical convergence zone to Last Glacial Maximum boundary conditions. Paleoceanography, 18, 1094, doi:10.1029/ 2003PA000916.

Codron, F., 2012: Ekman heat transport for slab oceans. Climate Dyn., 38, 379-389, doi:10.1007/s00382-011-1031-3.

Crueger, T., B. Stevens, and R. Brokopf, 2013: The Madden-Julian oscillation in ECHAM6 and the introduction of an objective MJO metric. J. Climate, 26, 3241-3257.

Cvijanovic, I., and J. C. H. Chiang, 2013: Global energy budget changes to high latitude North Atlantic cooling and the tropical ITCZ response. Climate Dyn., 40, 1435-1452, doi:10.1007/ s00382-012-1482-1.

, P. L. Langen, E. Kaas, and P. D. Ditlevsen, 2013: Southward intertropical convergence zone shifts and implications for an atmospheric bipolar seesaw. J. Climate, 26, 4121-4137.

Donohoe, A., and D. S. Battisti, 2011: Atmospheric and surface contributions to planetary albedo. J. Climate, 24, 44024418.

- D. M. Frierson, and D. S. Battisti, 2013a: The effect of ocean mixed layer depth on climate in slab ocean aquaplanet experiments. Climate Dyn., doi:10.1007/s00382-013-1843-4.

_ - J. Marshall, D. Ferreira, and D. Mcgee, 2013b: The relationship between ITCZ location and cross-equatorial atmospheric heat transport: From the seasonal cycle to the Last Glacial Maximum. J. Climate, 26, 3597-3618.

Frierson, D. M. W., and Y.-T. Hwang, 2012: Extratropical influence on ITCZ shifts in slab ocean simulations of global warming. J. Climate, 25, 720-730. 
Fuĉkar, N. S., S.-P. Xie, R. Farneti, E. A. Maroon, and D. M. W. Frierson, 2013: Influence of the extratropical ocean circulation on the intertropical convergence zone in an idealized coupled general circulation model. J. Climate, 26, 46124629.

Hatzianastassiou, N., A. Fotiadi, C. Matsoukas, K. Pavlakis, E. Drakakis, D. Hatzidimitriou, and I. Vardavas, 2004a: Longterm global distribution of Earth's shortwave radiation budget at the top of atmosphere. Atmos. Chem. Phys., 4, 1217-1235, doi:10.5194/acp-4-1217-2004.

_ C. Matsoukas, D. Hatzidimitriou, C. Pavlakis, M. Drakakis, and I. Vardavas, 2004b: Ten year radiation budget of the earth: 1984-93. Int. J. Climatol., 24, 1785-1802, doi:10.1002/ joc. 1110 .

Held, I. M., 2001: The partitioning of the poleward energy transport between the tropical ocean and atmosphere-ocean. J. Atmos. Sci., 58, 943-948.

Holbourn, A., W. Kuhnt, M. Regenberg, M. Schulz, A. Mix, and N. Andersen, 2010: Does Antarctic glaciation force migration of the tropical rain belt? Geology, 38, 783-786, doi:10.1130/G31043.1.

Hwang, Y.-T., and D. M. W. Frierson, 2010: Increasing atmospheric poleward energy transport with global warming. Geophys. Res. Lett., 37, L24807, doi:10.1029/2010GL045440.

$\longrightarrow$, and —_, 2013: Link between the double-intertropical convergence zone problem and cloud biases over the Southern Ocean. Proc. Natl. Acad. Sci. USA, 110, 4935-4940, doi:10.1073/ pnas.1213302110.

Jayne, S., and J. Marotzke, 2001: The dynamics of ocean heat transport variability. Rev. Geophys., 39, 385-411, doi:10.1029/ 2000RG000084.

Kang, S. M., I. M. Held, D. M. W. Frierson, and M. Zhao, 2008: The response of the ITCZ to extratropical thermal forcing: Idealized slab-ocean experiments with a GCM. J. Climate, 21, 3521-3532.

- D. M. W. Frierson, and I. M. Held, 2009: The tropical response to extratropical thermal forcing in an idealized GCM: The importance of radiative feedbacks and convective parameterization. J. Atmos. Sci., 66, 2812-2827.

Kato, S., 2009: Interannual variability of the global radiation budget. J. Climate, 22, 4893-4907.

Langen, P. L., R. G. Graversen, and T. Mauritsen, 2012: Separation of contributions from radiative feedbacks to polar amplification on an aquaplanet. J. Climate, 25, 3010-3024.

Loeb, N. G., B. A. Wielicki, D. R. Doelling, G. L. Smith, D. F. Keyes, S. Kato, N. Manalo-Smith, and T. Wong, 2009: Toward optimal closure of the earth's top-of-atmosphere radiation budget. J. Climate, 22, 748-766.

Lucarini, V., and F. Ragone, 2011: Energetics of climate model: Net energy balance and meridional enthalp transport. Rev. Geophys., 49, RG1001, doi:10.1029/2009RG000323.

Marshall, J., A. Donohoe, D. Ferreira, and D. McGee, 2013: The ocean's role in setting the mean position of the inter-tropical convergence zone. Climate Dyn., doi:10.1007/s00382-013-1767-z, in press.

Mauritsen, T., R. G. Graversen, D. Klocke, P. L. Langen, B. Stevens, and L. Tomassini, 2013: Climate feedback efficiency and synergy. Climate Dyn., 41, 2539-2554, doi:10.1007/s00382-013-1808-7.

McCarthy, M. P., J. Sanjay, B. B. B. Booth, K. Krishna Kumar, and R. A. Betts, 2012: The influence of vegetation on the ITCZ and South Asian monsoon in HadCM3. Earth Syst. Dyn., 3, 87-96, doi:10.5194/esd-3-87-2012.

Ming, Y., and V. Ramaswamy, 2011: A model investigation of aerosol-induced changes in tropical circulation. J. Climate, 24, $5125-5133$
Möbis, B., and B. Stevens, 2012: Factors controlling the position of the ITCZ on an aquaplanet. J. Adv. Model. Earth Syst., 4, M00A04, doi:10.1029/2012MS000199.

Nordeng, T. E., 1994: Extended versions of the convective parametrization scheme at ECMWF and their impact on the mean and transient activity of the model in the tropics. ECMWF Research Department Tech. Memo. 206, 41 pp.

Pahnke, K., J. P. Sachs, L. Keigwin, A. Timmermann, and S.-P. Xie, 2007: Eastern tropical Pacific hydrologic changes during the past 27,000 years from $\mathrm{D} / \mathrm{H}$ ratios in alkenones. Paleoceanography, 22, PA4214, doi:10.1029/2007PA001468.

Pierrehumbert, R. T., 1995: Thermostats, radiator fins, and the local runaway greenhouse. J. Atmos. Sci., 52, 1784-1806.

$\longrightarrow$, D. Abbot, A. Voigt, and D. Koll, 2011: Climate of the Neoproterozoic. Annu. Rev. Earth Planet. Sci., 39, 417-460, doi:10.1146/annurev-earth-040809-152447.

Ramanathan, V., 1987: The role of Earth radiation budget studies in climate and general circulation research. J. Geophys. Res. 92 (D4), 4075-4095, doi:10.1029/JD092iD04p04075.

, R. D. Cess, E. F. Harrison, P. Minnis, B. R. Barkstrom, E. Ahmad, and D. Hartmann, 1989: Cloud-radiative forcing and climate: Results from the Earth Radiation Budget Experiment. Science, 243, 57-63.

Rose, B. E. J., and D. Ferreira, 2013: Ocean heat transport and water vapor greenhouse in a warm equable climate: A new look at the low gradient paradox. J. Climate, 26, 21172136.

Sobel, A. H., J. Nilsson, and L. M. Polvani, 2001: The weak temperature gradient approximation and balanced tropical moisture waves. J. Atmos. Sci., 58, 3650-3665.

Soden, B. J., A. J. Broccoli, and R. S. Hemler, 2004: On the use of cloud forcing to estimate cloud feedback. J. Climate, 17, 36613665 .

Stevens, B., and Coauthors, 2013: The atmospheric component of the MPI-M Earth system model: ECHAM6. J. Adv. Model. Earth Syst., 5, 146-172, doi:10.1002/jame.20015.

Swann, A. L. S., I. Y. Fung, and J. C. H. Chiang, 2012: Mid-latitude afforestation shifts general circulation and tropical precipitation. Proc. Natl. Acad. Sci. USA, 109, 712-716, doi:10.1073/ pnas.1116706108.

Taylor, K. E., M. Crucifix, P. Braconnot, C. D. Hewitt, C. Doutriaux, A. J. Broccoli, J. F. B. Mitchell, and M. J. Webb, 2007: Estimating shortwave radiative forcing and response in climate models. J. Climate, 20, 2530-2543.

Tiedtke, M., 1989: A comprehensive mass flux scheme for cumulus parameterization in large-scale models. Mon. Wea. Rev., 117, 1779-1800.

Trenberth, K. E., and J. M. Caron, 2001: Estimates of meridional atmosphere and ocean heat transports. J. Climate, 14, $3433-$ 3443.

Voigt, A., and D. S. Abbot, 2012: Sea-ice dynamics strongly promote snowball Earth initiation and destabilize tropical sea-ice margins. Climate Past, 8, 2079-2092, doi:10.5194/ cp-8-2079-2012.

,,-- R. T. Pierrehumbert, and J. Marotzke, 2011: Initiation of a Marinoan snowball Earth in a state-of-the-art atmosphereocean general circulation model. Climate Past, 7, 249-263, doi:10.5194/cp-7-249-2011.

_ B. Btevens, J. Bader, and T. Mauritsen, 2013: The observed hemispheric symmetry in reflected shortwave irradiance. J. Climate, 26, 468-477.

Vonder Haar, T. H., and V. E. Suomi, 1971: Measurements of the earth's radiation budget from satellites during a five-year 
period. Part I: Extended time and space means. J. Atmos. Sci., 28, 305-314.

Wielicki, B., B. Barkstrom, E. Harrison, R. Lee III, G. Smith, and J. Cooper, 1996: Clouds and the Earth's Radiant Energy System (CERES): An Earth observing system experiment. Bull. Amer. Meteor. Soc., 77, 853-868.

Yoshimori, M., and A. J. Broccoli, 2008: Equilibrium response of an atmosphere-mixed layer ocean model to different radiative forcing agents: Global and zonal mean response. J. Climate, 21, 4399-4423.
— and - 2009: On the link between Hadley circulation changes and radiative feedback processes. Geophys. Res. Lett., 36, L20703, doi:10.1029/2009GL040488.

Zhang, R., S. M. Kang, and I. M. Held, 2010: Sensitivity of climate change induced by the weakening of the Atlantic meridional overturning circulation to cloud feedback. J. Climate, 23, 378-389.

Zhang, Y.-C., and W. B. Rossow, 1997: Estimating meridional energy transports by the atmospheric and oceanic general circulations using boundary fluxes. J. Climate, 10, 2358-2373. 
Copyright of Journal of Climate is the property of American Meteorological Society and its content may not be copied or emailed to multiple sites or posted to a listserv without the copyright holder's express written permission. However, users may print, download, or email articles for individual use. 